\title{
Managing Collaborative Innovation: How to Reduce the Signs of Job Burnout Stress for College Counselors on Campus?
}

\author{
Fenghua Liu ${ }^{1}$ Wei-Ta Fang ${ }^{2}$,* \\ ${ }^{1}$ Students Affairs Office, Shandong University, Weihai \\ ${ }^{2}$ Graduate Institute of Environmental Education, National Taiwan Normal University, \\ Taipei (*corresponding author)
}

\begin{abstract}
The signs of job burnout stress in college counselors have tremendous influences on college students. These, thus, becomes crucial to invent emphasized mechanism on preventing their stress. This empirical study has used randomly selective samples in questionnaires to apply full-time counselors on campus in Shandong Province during 2012. We found that the psychological states of the counselors' emotional exhaustion are not significantly optimistic. Nearly $60 \%$ of the subjects have detected negative emotions (i.e., tiredness, anxiety and nervousness, etc.) from the influential internal and external factors (i.e., counseling students, career years, and marital status). Therefore, managing collaborative innovation is required on campus to meet the request of Motivation-Hygiene Theory.
\end{abstract}

Keywords: education science, organizational innovation, Motivation-Hygiene Theory, Maslach Burnout Inventory (MBI)

\section{Managing Collaborative Stress}

According to Maslach's theory, job burnout stress is narrated by emotional exhaustion, depersonalization, and low personal achievement $[1,2]$. Helpless in facing of their cases, college counselors meet schools', social and self-imposed expectations on their professional roles, and often face major grief deprivation, even leading to the phenomenon of professional exhaustion. However, very few documents have been detected for their psychological health on the campus of colleges \& universities in Chinese Society. Some cases studies by questionnaires have been detected from their experiences of coping with grief while they face multi-faceted student sorrows in situational teaching on campus. The concepts of managing collaborative innovation for counselors have been provided to find solutions to release and prevent their job burnout signs.

\section{Research Methods}

This study was randomly selected effective 260 questionnaires partially by $\mathrm{E}$ mail from full-time counselors on the campus from colleges \& universities in Shandong Province, China [3]. This study applies Maslach Burnout Inventory (MBI) which was revised by Beijing Normal University with consisting of their three dimensions: emotion exhaustion, depersonalization, and low personal achievement. We designed 22 sample self-assessment questions presented using a five-point Likert scale, among which 8 are categorized to emotional exhaustion, 6 , to depersonalization, and resting 8 , to 
low personal achievement. The higher the score, the more serious the state of their job burnout stress on campus from MBI.

\section{Results}

\subsection{Descriptive statement}

The average age of these 260 counselors is 31 years old at an average 5 working years. Among our study targets, males were accounted for $51.6 \%$, while females were accounted for $48.4 \%$. The proportion of these college counselors whose age is $40.9 \%$ between 21 to 30, and only $2 \%$ of them are older than the age of 41 , indicating that the most of counselors are relatively young with regular state of marriage at a rate of $76.3 \%$. Over $97.1 \%$ of the college counselors have junior and intermediate professional titles.

The average number of their caring students is 277 per person at a regular higher rate. In China, the career situation of college counselors' work is categorized both at managerial administration and ideological education. They can achieve final titles, such as deputy section chief, section chief, deputy director, and director from self-realization from their title assessment in future career plans. However, compared with professional teachers as professors on campus who have the same titles, half of counselors think their wages treatment is relatively lower. Compared with managers who took a job begun in the same level year, $66.7 \%$ of counselors thought their positions are relatively lower. When it comes to the equivalent policies of whether to separate counselors' evaluation process with the same standards of values from other teachers, only one third of colleges have adopted this policy as managing collaborative innovation, or the rests have not.

\subsection{The Likert-scale scores}

It can be seen in the table 1 , the total av- erage score of college counselors in this survey is a lower score at a rate of $1.77 \pm$ 0.27 with only $2.95 \%$ of respondents greater than that of the rate of 3 at a fivepoint Likert scale. The phenomenon of job burnout are obvious from emotional exhaustion $(2.06 \pm 0.43)$, low personal achievement $(1.70 \pm 0.38)$, and depersonalization $(1.56 \pm 0.37)$, respectively. The higher the score more than 3 accounted for the percentage of $5.98 \%$, the more serious the state of their job burnout stress on the values of emotional exhaustion.

Table 1: The average and standard deviation of each factor around counselors' job burnout using a five-point Likert scale.

\begin{tabular}{lllll}
\hline factors & M & S.D & $>2$ & $>3$ \\
\hline EE & 2.06 & 0.43 & $57.8 \%$ & $5.89 \%$ \\
LPA & 1.70 & 0.38 & $23 \%$ & $2.95 \%$ \\
$\begin{array}{l}\text { deper- } \\
\text { sonaliz } \\
\text { ation }\end{array}$ & 1.56 & 0.37 & $17 \%$ & $2.95 \%$ \\
JB & 1.77 & 0.27 & $19.3 \%$ & $2.95 \%$ \\
\hline
\end{tabular}

Note: M: mean; S.D.: standard deviation; EE: emotional exhaustion; LPA: low personal achievement; JB: job burnout.

Table 2: The t-test on the three dimensions with various caring students' scales.

\begin{tabular}{llll}
\hline factors & $\begin{array}{l}>200 \\
(\mathrm{sn}=131) \\
(\mathrm{M} \pm \text { S.D. }\end{array}$ & $\begin{array}{l}<200 \\
(\mathrm{sn}=129) \\
(\mathrm{M} \pm \text { S.D. })\end{array}$ & T test \\
\hline EE & $2.11 \pm 0.45$ & $1.99 \pm 0.40$ & $2.131^{*}$ \\
LPA & $1.72 \pm 0.43$ & $1.67 \pm 0.31$ & 1.295 \\
$\begin{array}{l}\text { deper- } \\
\text { sonaliz } \\
\text { ation }\end{array}$ & $1.61 \pm 0.38$ & $1.50 \pm 0.34$ & $2.045^{*}$ \\
\hline
\end{tabular}

Note: sn: student number; M: mean; S.D.: standard deviation; EE: emotional exhaustion; LPA: low personal achievement; JB: job burnout.

From the T-test, the caring numbers of students have led negative influences both on emotional exhaustion and deper- 
sonalization. College counselors turned a relatively stress-trend whose caring students have been accounted greater than the caring number of 200 compared with that of less caring students. This trend reflected on the value of emotional exhaustion $\left(\chi^{2}=121.9 ; \mathrm{p}=0.00\right)$.

Table 3: The t-test on the three dimensions with marital status

\begin{tabular}{lccc}
\hline factors & $\begin{array}{c}\text { unmarried } \\
(\mathrm{M} \pm \text { S.D. })\end{array}$ & $\begin{array}{l}\text { married } \\
(\mathrm{M} \pm \text { S.D. })\end{array}$ & T test \\
\hline EE & $1.88 \pm 0.39$ & $2.08 \pm 0.43$ & $-2.177^{*}$ \\
LPA & $1.66 \pm 0.35$ & $1.71 \pm 0.40$ & -1.590 \\
$\begin{array}{l}\text { deper- } \\
\text { sonaliz } \\
\text { ation }\end{array}$ & $1.48 \pm 0.32$ & $1.60 \pm 0.36$ & -0.611 \\
\hline
\end{tabular}

Note: M: mean; S.D.: standard deviation; EE: emotional exhaustion; LPA: low personal achievement; JB: job burnout.

The T-test also detected that married counselors reached relatively higher scores $(2.08 \pm 0.43)$ at the dimension of emotional exhaustion compared with that of unmarried respondents $(1.88 \pm 0.39)$. Facing various pressures from students' mental affairs, the married counselors are easy to be anxious, depressed, and fretful both at their careers and their family life while they ought to be in charge of double or multiple duties mentally and physically $\left(\chi^{2}=23.5 ; \mathrm{p}=0.00\right)$.

The one-way ANOVA approach demonstrated that the major reason was significant at emotional exhaustion from internal and external factors, students and their families. The post-hoc test also determined that the junior college counselors with enthusiasm, less than one year,were much happier with lower burnout rate (1.8) compared than that of the senior college counselors (2.2) with a relative burn-out symptom. The junior college counselors' scores at all three dimensions indicated that they could fully enjoy their jobs with lowest emotional exhaustion, lowest depersonalization, and highest personal achievement (Fig. 1).

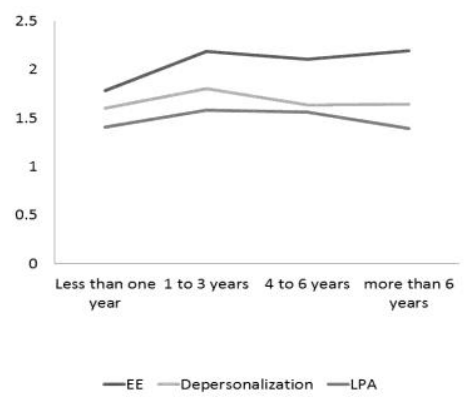

Fig. 1: Working years ( $>1$ year) regarding to job burnout rate, especially at the dimension of emotional exhaustion.

\section{Discussions}

Regarding to our final findings from the reasons of job burnout for a senior college counselors, we detected that working years, working loadings, and family burden are three killers to kill their vocational enthusiasm for counselors (Fig. 2). In some colleges of Shandong Province, the situation of college counselors' job burnout is not optimistic, and the symptom of emotional exhaustion has been detected very obvious. Nearly $60 \%$ of the respondents have negative emotions (i.e., fatigue, anxiety, and nervousness), and they talked to us their stresses ought to be remedied. From this study, we can see that the college counselors with great loading signs in turns of emotional exhaustion, depersonalization, and lower personal achievement.

Why these senior counselors are not willing to contribute their experiences for their knowledge as younger counselors since they have personal and family's distress? Can we find relatively motivation theory to urge staffs to be re-looking for their refreshed values of collaborative innovation in institutes to work hard as well as motivated freshmen in colleges to play hard? 


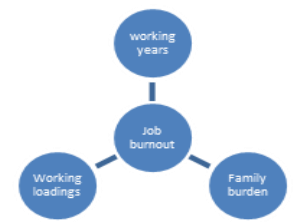

Fig. 2: Job burnout ought to be reduced from internal factors (i.e., working years and loadings) and external factors (i.e., family burden) from temporal and numerical charges.

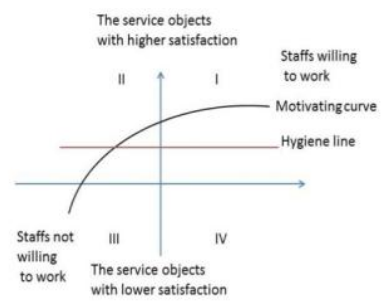

Fig. 3: Managing collaborative innovation applied to a refined theory named Motivation-Hygiene Theory. Staffs located at third quadrant (III) have been requested to retired and/or quitted jobs; located at second quadrant (II) have been considered to improve basic salaries as well as increase other motivation factors; and located at fourth quadrant (IV) have been requested to learn more practical career trainings. According to Herzberg et al. (1959), there are two factors could be reduced job burnout stress from the Motivation-Hygiene Theory [4]. Motivating factors are able to urge employees with high satisfaction and hygiene factors can be only eliminated the feelings of employee's dissatisfaction. Motivation factors are described: the work itself, work identity, self-growth, promotion, professional development, selfresponsibility and achievements. Hygiene factors are described: salary, governance, work status, job security, working environment, personal life, organizational policy and interpersonal relationships.

In the second quadrant (II) (see Fig. 3), the staffs are not willing to work, but their performance is not so bad, and their employers are also satisfied from their performance. Since the status of the staffs may occur job burn-out trends, the employers are willing to retain employees from quitting jobs since their excellent experiences. Based on Herzberg's Motivation-Hygiene Theory, the senior employees have given all hygiene factors, such as: salary, working status \& loadings, job security, working environment, and fine personal relationships, they should reconsider their motivation factors as well as their family lives and values.

\section{Conclusion}

Collaborative innovation is a new concept for decision makers to encourage their colleagues and staffs to work efficiency from multi-functional approaches. All motivation factors as well as hygiene factors are useful to design innovated organization and new motivation processes. We detected that if the college counselors could be released their job burnout burdens, and aroused their working enthusiasm and initiative; it might be helpful to rotate their works from professional development with others appropriately. It might be also useful to improve their professional training to enhance their occupational identity by personal development.

\section{References}

[1] Y. Li, "The Comparative Study on the Job Burnout of People from Three Different Occupations," the Perspective of Integration, 2005.

[2] C. Maslach, C, "Job burnout: New directions in research and intervention, " Current Directions in Psychological Science, pp. 189-192, 2003.

[3] http//www.edu.cn/20060801/3202145 .shtm[120060801].

[4] F. Herzberg, B. Mausner, and B. Snyderman, The motivation to Work, 2nd ed. New York, NY: Wiley, 1959. 